\title{
A REGIONAL STUDY OF SOME OSMOTIC, IONIC AND AGE FACTORS AFFECTING THE STABILITY OF CEREBRAL LYSOSOMES ${ }^{1}$
}

\author{
O. Z. Sellinger and Linda M. NordRum \\ Mental Health Research Institute, University of Michigan Medical Center, \\ Ann Arbor, Michigan, 48104
}

(Received 13 December 1968. Accepted 21 February 1969)

\begin{abstract}
An examination was made of the effect of changes in the osmolarity and the ionic composition of the homogenizing medium on the partition of lysosomal arylsulphatase and $N$-acetylglucosaminidase of cerebral cortex, hypothalamus and thalamus of the rat. Sulphatase appeared to be more sensitive to hypotonicity than glucosaminidase, since a higher proportion of the sulphatase was released from the lysosomes into the soluble fraction of the cells from all three neuroanatomical areas examined. In the presence of $250 \mathrm{~mm}$-sucrose, supplementation with $10 \mathrm{~mm}-\mathrm{Mg}$ led to clumping of the lysosomes and their translocation into the heavy-particulate fraction; no such effect of $10 \mathrm{~mm}-\mathrm{Mg}$ was noted in the absence of 250 mm-sucrose.

The intracellular distribution of bound $N$-acetylneuraminic acid (bound-NANA) was also examined. The shifts observed in its intracellular localization as a result of changes in the ionic composition of the homogenizing medium rule out bound-NANA as a structural component of the membrane of the cortical lysosome. However regional differences in the response of bound-NANA to ionic factors were observed.

Lysosomes from cerebral cortex of adult and 12-day-old rats were also compared. Differences in the pattern of distribution of lysosomes in linear sucrose gradients and in response to ionic factors were uncovered.

The results support the previously enunciated concept (SELLINGER and HIATT, 1968) of a regional microheterogeneity of lysosomes and add a new, age-related dimension to it.
\end{abstract}

SINCE a recent comprehensive review (Novikoff, 1967) a number of reports have been added to the growing literature on lysosomes of neutral tissues. In our laboratory interest has focused chiefly on a comparison of lysosomes in different regions of the rat brain (SELlinger and HiatT, 1968), while other workers have studied lysosomes in the neurons of the superior cervical ganglion (DIXON, 1967), in dorsal root ganglia (NovikofF, 1967), in spinal cord motoneurons (KHATTAB, 1967) and in cortical neurons (Kreutzberg and Hager, 1966; Gordon, BenSCH, DeANIN and Gordon, 1968). A number of acid hydrolases (Taha and Carubelli, 1967; Frohwein and GATT, 1967; ALBERT, 1968; BowEN and RADIN, 1968), singly or as components of a multienzyme battery for the total hydrolysis of monosialogangliosides (GATT, 1967) or phosphoproteins (ALBERT, 1968) have been added to the list of brain lysosomal enzymes. As with hepatic lysosomal enzymes (BECK and TAPPEL, 1968), a distinction has become apparent between the hydrolases tightly bound to the lysosomal matrix (BOWEN and RADIN, 1968) and those relatively free of structural attachment (SELlinger and Hiatt, 1968). Age-related changes (Taha and Carubelli; Carubelli, 1968; Kerekes, FeszT, BeCus and Szekely, 1968; Bowen and RAdIN, 1969) in total enzyme activity and in the susceptibility of lysosomes to exogenous agents and factors

${ }_{1}$ Supported by grant NB 06294 of the United States Public Health Service. This is paper V in a series on cerebral lysosomes; consult SELLINGER and HIATr (1968) for the previous paper in the series.

Abbreviation used: NPG-ase, $N$-acetylglucosaminidase. 
(Sellinger and Rucker, 1966; KhatTab, 1967; DVorak, 1967; Verity and Brown, 1968) have also been uncovered. Evidence, therefore, seems to support the previously suggested premise (SELLINGER and HIATT, 1968) that inter-regional (and other) differences in enzyme activity and/or properties may reflect a microheterogeneity of lysosomes, which in turn, may aid in the biochemical characterization of a given brain structure known to be endowed with a specific function (see also VERITY and BROWN, 1968).

The present report describes the results of a study in which a systematic appraisal of several properties of cerebral lysosomes was made in an effort to uncover and possibly specify inter-regional and age-related differences amongst them

\section{EXPERIMENTAL PROCEDURE}

\section{Materials}

Chemicals. The substrates for the assay of the activities of the two enzymes were: 0 -nitrocatechol sulphate (K salt) for aryl-sulphate sulphohydrolase (arylsulphatase; EC 3.1.6.1) and $o$-nitrophenyl-2acetamido-2-deoxy- $\beta$-D-glucopyranoside for $\beta$-2-acetamido-2-deoxy-D-glucosideacetamidodeoxyglucohydrolase, (NPG-ase EC 3.2.1.30), obtained from Sigma Co., St. Louis, Mo. and Pierce Chemical Co., Rockford, Ill. $N$-Acetylneuraminic acid (NANA) was obtained from Light. Co., Colnbrooke, England; $o$-nitrocatechol from Sigma Co. and $o$-nitrophenol from Distillation Products, Rochester, N.Y. Sucrose (enzyme grade) and bovine serum albumin were obtained from Mann Chem. Co., New York City. Other reagents were of the best available analytical grade.

Animals. The rats were Sprague-Dawley adults (250-300 g) and 12 days old. Both sexes were used.

\section{Methods}

Analytical. Protein was determined according to Lowry, Rosebrough, FarR and RANDall (1951), with bovine serum albumin as standard; and bound-NANA was determined according to WARREN (1959). All preparations were thoroughly dialysed for at least $24 \mathrm{hr}$ against several changes of distilled water at $4^{\circ}$ before hydrolysis of the bound-NANA was carried out. The absorbancy at $549 \mathrm{~m} \mu$ was corrected for the absorbancy at $532 \mathrm{~m} \mu$ using the equation proposed by WARREN (1959).

Centrifugations. After dissection and weighing, the cerebral cortex (from one rat), hypothalami (from six rats) or thalami (from six rats) were homogenized for $30 \mathrm{sec}$ in the medium indicated (see below) at about $1300 \mathrm{rev}$./min with a motor-driven stainless steel-Teflon pestle. The volume was adjusted to a $10-15 \%(\mathrm{w} / \mathrm{v})$ homogenate, and the suspension was centrifuged for $10 \mathrm{~min}$ at $25,000 \mathrm{~g}$ (Sorvall rotor SS-34). The sediment was resuspended in one-half the original volume of medium and the above centrifugation was repeated. The final pellet, suspended in $2 \mathrm{ml}$ of $0.25 \mathrm{M}$-sucrose, was layered on top of $15 \mathrm{ml}$ of $0.9 \mathrm{M}$-sucrose which, in turn, had been layered on $10 \mathrm{ml}$ of $1.4 \mathrm{M}$-sucrose. Centrifugation (at 63,000 g for $30 \mathrm{~min}$; Spinco rotor $S W 25 \cdot 1$, brake off) separated myelin (fraction $M y$ ) floating on the $0.9 \mathrm{M}$-sucrose, from a particulate fraction layered on top of the $1.4 \mathrm{M}$-sucrose (fraction NEML) with the following contents, depending on the composition of the homogenization medium (see below): the nerve endings, the mitochondria and the lysosomes, or, if the medium was not $0.25 \mathrm{M}$-sucrose, the membranous remnants and fragments of these subcellular particles. The pellet contained material which had traversed $1.4 \mathrm{M}$-sucrose and was designated as the crude fraction Ly. For the separation of the microsomal fraction (Mic), the supernatant remaining after the second $25,000 \mathrm{~g}$ step (see above) was centrifuged for $45 \mathrm{~min}$ at $269,000 \mathrm{~g}$ to yield the Mic pellet and soluble fraction $S$. All fractions isolated as bands on a discontinuous gradient were spun down from a volume of $11.5 \mathrm{ml}$ by centrifugation at $269,000 \mathrm{~g}$ for $50 \mathrm{~min}$. Crude fraction $L y$ was resuspended and centrifuged at $269,000 \mathrm{~g}$ for $45 \mathrm{~min}$. The resulting pellet (fraction $L y$ ) was subjected to gradient centrifugation as follows: up to $1.5 \mathrm{ml}$ of a suspension of fraction $L y$ were layered on the linear sucrose gradient $(5.5 \mathrm{ml}$, Beckman cellulose nitrate tube No. 302232) which was centrifuged for $2.5 \mathrm{hr}$ at $63,500 \mathrm{~g}$ The gradient was pumped through a hole punched in the bottom of the centrifuge tube into test tubes resting in fraction collector racks (LKB UltroRac) and collected at a rate of $10 \mathrm{drops} /$ tube.

Enzymes. The conditions of assay were as described in detail previously (SELLINGER and HIATT, 1968). For simplicity, activity of enzymes is expressed in this paper as units/g, defined as absorbancy (at $515 \mathrm{~m} \mu$ for sulphatase and at $412 \mathrm{~m} / \iota$ for NPG-ase)/hr/g. 
RESULTS

The intracellular distribution of sulphatase and NPG-ase in the cerebral cortex, the hypothalamus and the thalamus: effects of hypotonicity and of $10 \mathrm{mM}-\mathrm{Mg}$. Differential centrifugations were carried out in $250 \mathrm{~mm}-, 125 \mathrm{~mm}$ - or $60 \mathrm{~mm}$-sucrose, and the distribution of the enzymes and of protein was determined three consecutive times in each of the sucrose solutions and for each of the brain regions (Table 1; Fig. 1). Closely similar values were obtained, the individual sprẹad being less than 15 per cent. In addition to fractions $L y$ and $S$ (Fig. 1), hypotonicity had an appreciable effect on the partition of the enzymes between fractions NEML and Mic (not shown graphically), particularly when $125 \mathrm{~mm}$-sucrose was substituted for $250 \mathrm{~mm}$-sucrose. This caused a drop of about 20 per cent in the activities of sulphatase and the NPG-ase of fraction $N E M L$ and a parallel rise of activities in fraction Mic. Decreasing the sucrose concentration to $60 \mathrm{mM}$ failed to affect the partition of the enzymes any further.

Recently, a homogenizing medium consisting of $10 \mathrm{~mm}-\mathrm{Mg}$ acetate and $20 \mathrm{~mm}-$

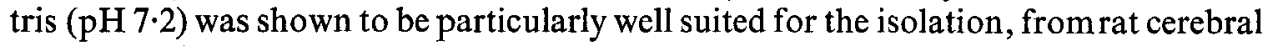
cortex, of a microsomal fraction containing few, if any, free polysomes (unattached to membranes) (Azcurra and Sellinger, 1967; Sellinger and Azcurra, 1968), as well as for isolation of electrophoretically homogeneous synaptic membranes (SEllinger and Borens, 1969). When this medium was superimposed on conditions of iso- and hypo-tonicity (Fig. 2), activities of sulphatase and NPG-ase in fraction $L y$ decreased sharply, while they increased in fraction $S$, whenever sucrose was omitted from the homogenization medium. Homogenization in tris $+\mathrm{Mg}$, followed immediately by dilution to $250 \mathrm{~mm}$ in sucrose, failed to prevent the solubilization of sulphatase, while somewhat halting that of NPG-ase. In the absence of sucrose, tris alone or tris $+\mathrm{Mg}$ had comparable effects on both enzymes. The complete medium (sucrose + tris $+\mathrm{Mg}$ ) as well as the medium containing tris $+\mathrm{Mg}$ were associated with virtually total depletion of sulphatase and NPG-ase in fraction $L y$; in the complete medium, however, both enzymes were retained in fraction $N E M L$ rather than rendered non-sedimentable, while, in the latter medium, solubilization of the hydrolases was the chief effect.

The analysis of the apparently separable effects of $\mathrm{Mg}$, when present alone or when present together with $250 \mathrm{~mm}$-sucrose, was extended to a determination of the relative specific activities (RSA = percentage of total enzyme (or NANA)/percentage of total protein) for both enzymes in the cerebral cortex, hypothalamus and thalamus (Fig. 3). Assays of bound-NANA were included in order to compare the shifts of this membrane marker (Sellinger and Borens, 1969; Sellinger, Borens and Nordrum, 1969) as a function of the $\mathrm{Mg}$ content and/or the tonicity of the homogenizing medium. There was a progressive decline of the RSA of sulphatase in fraction $L y$ in all three regions (compare media $\mathrm{A}, \mathrm{B}$ and $\mathrm{C}$ ). The effect of $60 \mathrm{~mm}$-sucrose was particularly striking in the case of the cortical enzyme. The decline in RSA of NPG-ase of fraction $L y$ in the hypothalamus and thalamus was less pronounced, although clearly visible (A vs. B). Medium $\mathrm{E}$ (hypotonic $\mathrm{Mg}$ ) was associated with the sharpest reduction of the RSA for both enzymes in fraction $L y$.

The distribution of protein among the five subcellular fractions (Table 2) shows that $10 \mathrm{~mm}-\mathrm{Mg}$ was associated with a considerable translocation of protein from fractions $M y, L y$ and $M i c$ into fraction $N E M L$ (compare lines 1 and 2 and lines 3 and 4, respectively). This translocating effect of $\mathrm{Mg}$ was also evident in terms of the 


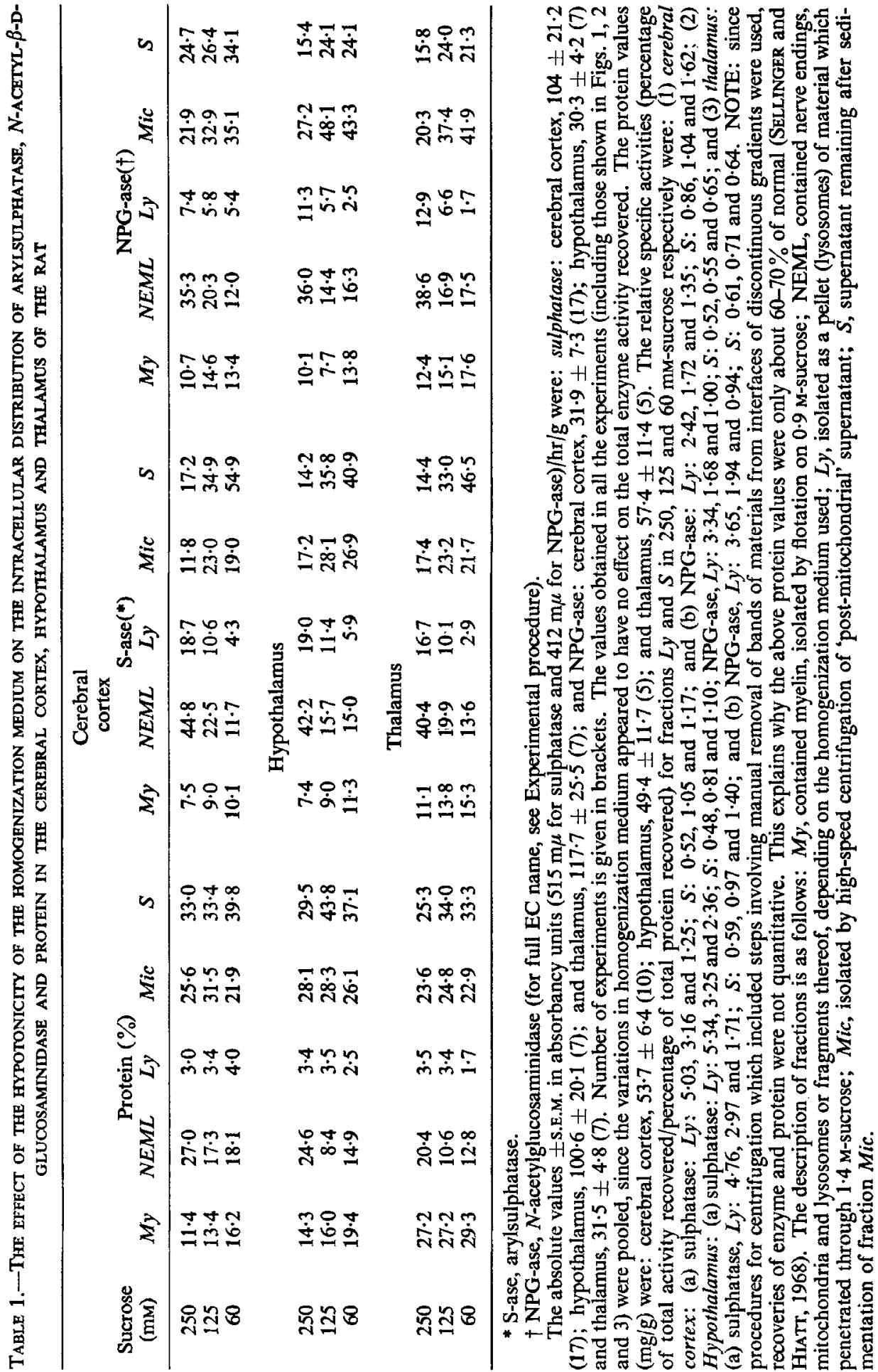


presence or absence of sucrose (compare line 2 to line 4), but, under these conditions, the migration of protein toward fraction $N E M L$ was chiefly from fraction $S$ (cortex and hypothalamus) and $M y$ (thalamus).

The effect of hypotonicity on the RSA of bound-NANA was different in the three regions examined (Fig. 3). In the samples from cerebral cortex there was virtually no effect, there being two peak RSAs (fractions $M y$ and $M i c$ ) irrespective of the sucrose concentration used (media A, B and C). In the samples from hypothalamus and

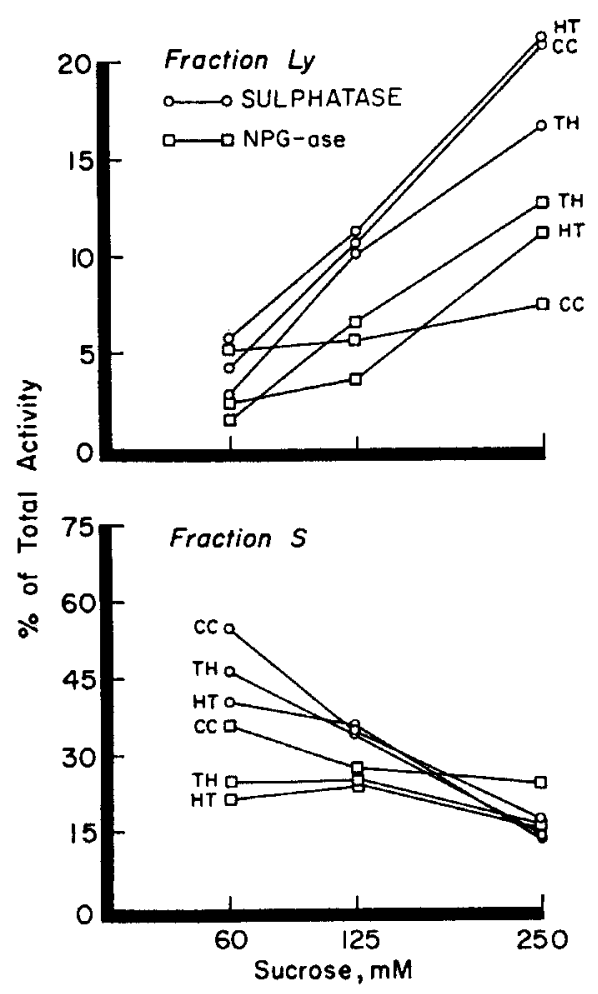

Fic. 1.-The effect of hypotonicity on the partition of sulphatase and $\mathrm{N}$-acetylglucosaminidase (NPG-ase) between the lysosomal fraction $(L y)$ and the soluble fraction $(S)$. Ordinate, percentage of the sum of the activities recovered in fractions $M y, N E M L$, $L y, M i c$ and $S$ (for description, see legend to Table 1); $\bigcirc-O$, sulphatase; $\square-\square$, NPG-ase.

thalamus, the peak RSA for microsomes was unaffected, yet an increase in hypotonicity appeared to result in an increase in the RSA of bound-NANA in hypothalamic fractions $M y$ and $L y$ and in thalamic fraction $L y$. Relatively high RSA values of bound-NANA were also noted in thalamic fraction $L y$ after isolation in medium D.

The effect of $\mathrm{Mg}$ was most striking in medium $\mathrm{E}$ where fractions $M y$ and $N E M L$ exhibited high values for RSA. The shift of bound-NANA to fraction $N E M L$ was not strictly parallel to a similar shift of protein since the latter accumulated in fraction $N E M L$ when medium D was used (Table 2). 
Comparison of the intracellular distribution of sulphatase and NPG-ase in the cerebral cortex of 12-day-old and adult rats. Differential centrifugation in $250 \mathrm{~mm}$-sucrose was performed in parallel on homogenates of cerebral cortex from 12-day-old and adult rats and the values for RSA were calculated (Fig. 4, upper half). Peak RSAs were found in fraction $L y$. These experiments also revealed that the protein contents of
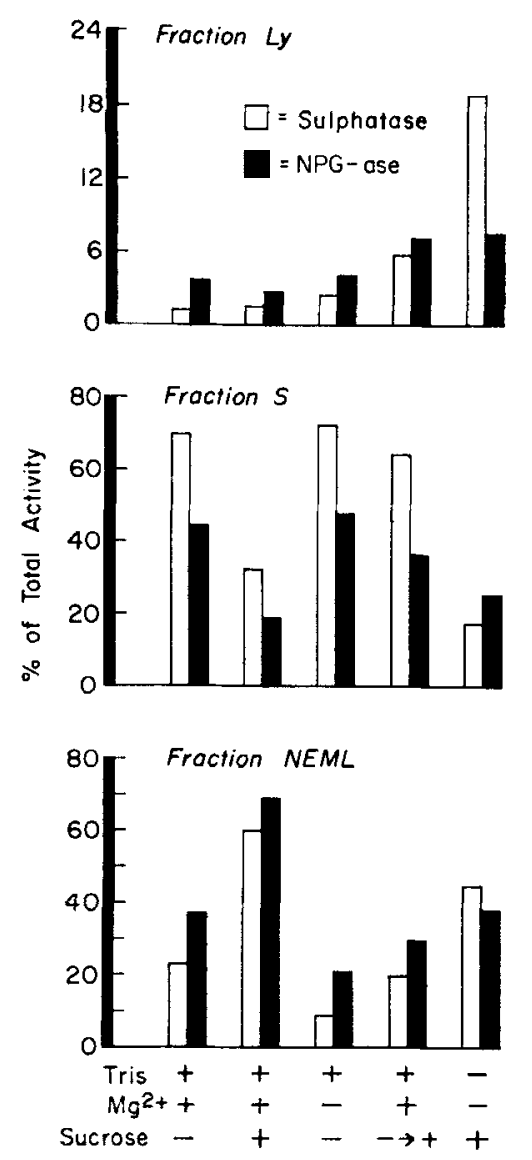

FIG. 2.-The effect of ionic and osmotic factors, alone or in combination, on the partition of sulphatase and $\mathrm{N}$-acetylglucosaminidase (NPG-ase) from cerebral cortex between fractions $N E M L, L y$ and $S$ (for description, see legend, Table 1). Ordinate, as in Fig. 1; tris, $20 \mathrm{~mm}$ (pH 7.2); $\mathrm{Mg}, 10 \mathrm{~mm}$; sucrose, $250 \mathrm{~mm}$.

fractions $N E M L, L y$ and $M i c$ of the 12-day-old and the adult cortices were noticeably different (Table 2) while those of fraction $S$ were not. Examination of the effect of medium D (Fig. 3) on the intracellular distribution of the two hydrolases in the 12-dayold cortex (Fig. 4, lower half) showed a RSA profile different from that of the adult, inasmuch as the former was devoid of peaks.

Fraction $L y$, isolated in $250 \mathrm{~mm}$-sucrose from 12-day-old cortex and containing, in two consecutive experiments, 26.1 and 30.7 per cent of the total sulphatase and 18.0 and 22.7 per cent of the total NPG-ase activity, was subjected to gradient centrifugation (see Methods). Fraction $L y$ isolated in parallel from adult cortices was treated similarly. The results confirmed the existence of two populations of lysosomes 
(SELlinger and HiATt, 1968): a heavy one penetrating $50 \%(\mathrm{w} / \mathrm{v})$ sucrose and a heterogeneous, lighter one, rather diffusely distributed throughout the gradient. No significant differences were noted in the proportions of either population when 12-dayolds and adults were compared. The specific activities of sulphatase and NPG-ase in fraction $L y$ of 12-day-olds were both higher than in fraction $L y$ from adults (Table 3 ) by a factor of 3 . The specific activities of the hydrolases in the gradient pellet, although appreciably higher than those of fraction $L y$ (see B/A values), became virtually

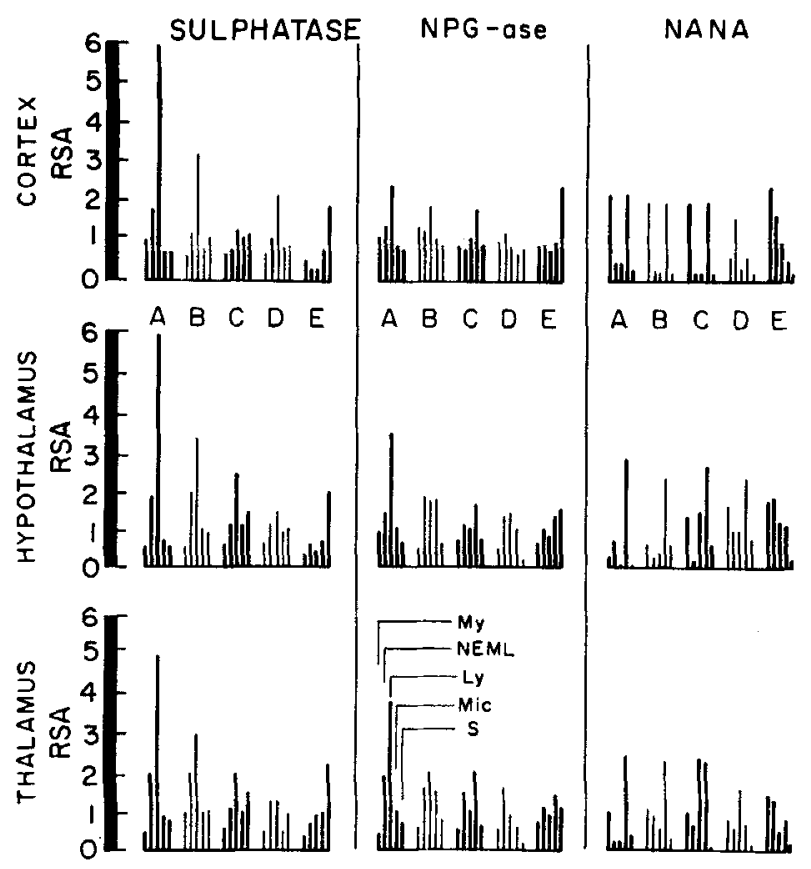

FIG. 3.-The effect of osmotic and ionic factors, alone or in combination, on the relative specific activity (RSA) of sulphatase, $N$-acetylglucosaminidase (NPG-ase) and bound $N$-acetylneuraminic acid (NANA) in the cerebral cortex, the hypothalamus and the thalamus of the adult rat. The bar width has no significance; the bar height measures RSA. The following media were used: A, $250 \mathrm{~mm}$-sucrose; B, $125 \mathrm{~mm}$ sucrose; C, $60 \mathrm{~mm}$-sucrose; $\mathrm{D}, 20 \mathrm{~mm}$ tris $(\mathrm{pH} 7 \cdot 2)+10 \mathrm{mM}-\mathrm{Mg}+250 \mathrm{~m}$ M-sucrose; E: 20 mM-tris (pH 7-2) $+10 \mathrm{~mm} \mathrm{Mg.} \mathrm{For} \mathrm{description} \mathrm{of} \mathrm{fractions} \mathrm{see} \mathrm{legend,} \mathrm{Table} 1$.

identical for NPG-ase in the 12-day-old and the adult brains, (Table 3), but not for sulphatase.

\section{DISCUSSION}

Although the procedure for tissue fractionation adopted in the present experiments differs appreciably from that used previously (SELLINGER, RUCKER and DE BALBIAN Verster, 1964; SELlinger and HiATT, 1968) distinct subcellular fractions were separated effectively and with the added advantages of providing an extra fraction $M y$, and a purer lysosomal fraction (fraction $L y$ ). Indeed, both hydrolases exhibited values for RSA between 5 and 6 in fraction $L y$ (Fig. 3, medium A) compared to values for RSA of about 2 in fraction L of SELLINGER and HiATT (1968).

The intracellular distribution of bound-NANA (Fig. 3, medium A) exhibited 


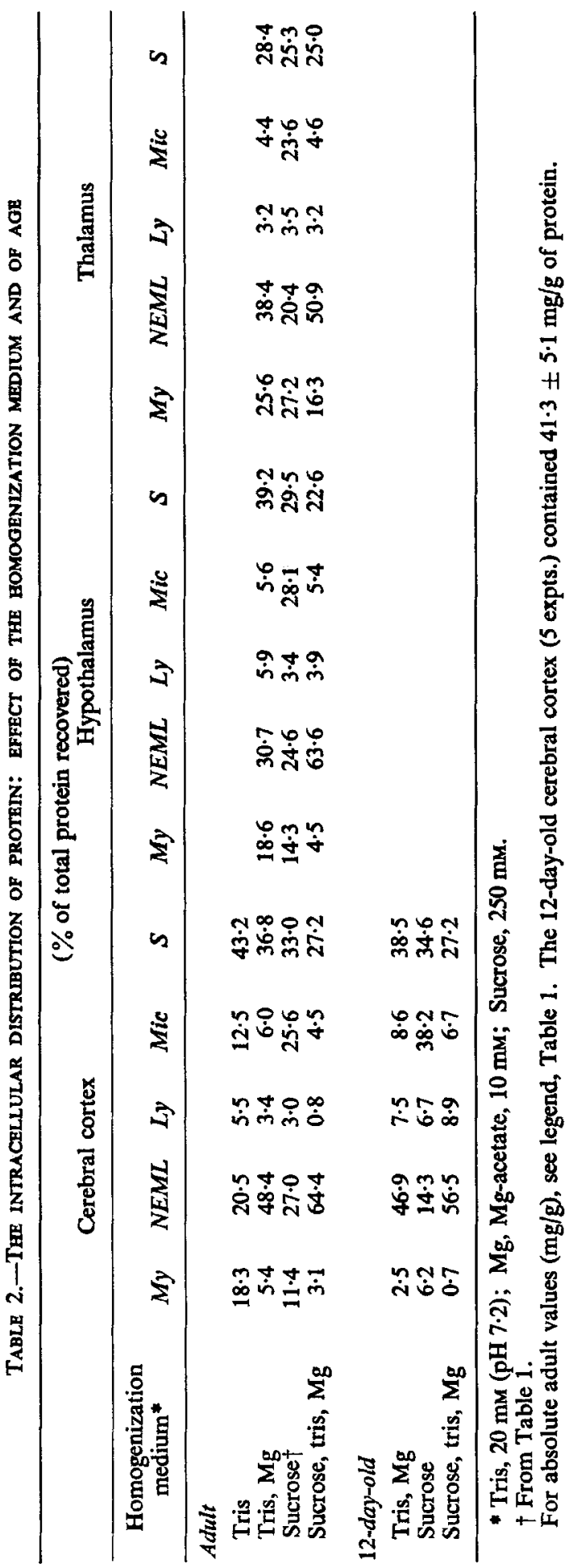



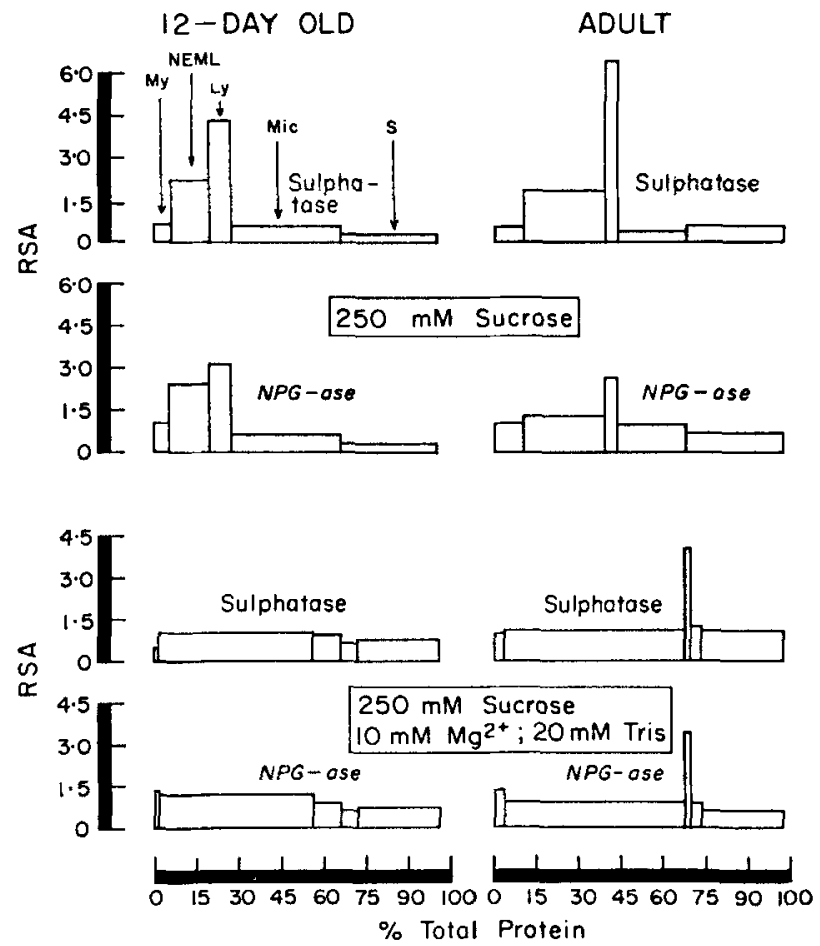

FIg. 4.-A comparison of the effects of $10 \mathrm{mM}-\mathrm{Mg}+20 \mathrm{mM}$-tris $(\mathrm{pH} 7 \cdot 2)$ on the relative specific activity (RSA) of sulphatase and $N$-acetylglucosaminidase (NPG-ase) in the subcellular fractions of cerebral cortex from the 12-day-old and adult rat.

TABLe 3.-GRAdient CENTRIFUgation OF LySOSOMES FROM 12-day-OLD AND ADULT bRAin

\begin{tabular}{lcccc}
\hline & \multicolumn{2}{c}{$12-D a y-o l d$} & \multicolumn{2}{c}{ Adult } \\
\hline \multicolumn{1}{c}{ Fraction } & Sulphatase & NPG-ase & Sulphatase & NPG-ase \\
& & \multicolumn{2}{c}{ (units/mg)* } & \\
\hline A. Ly ${ }^{*}$ & $11 \cdot 3 \pm 2 \cdot 6[6]$ & $2 \cdot 42 \pm 0 \cdot 8[6]$ & $4 \cdot 40 \pm 1 \cdot 0[5]$ & $0 \cdot 71 \pm 0 \cdot 30[5]$ \\
B. Gradient pellet + & $42 \cdot 5[3]$ & $10 \cdot 3[3]$ & $29 \cdot 2[3]$ & $9 \cdot 1[3]$ \\
B/A & $(32 \cdot 0-54 \cdot 5)$ & $(5 \cdot 9-16 \cdot 8)$ & $(16 \cdot 8-50 \cdot 5)$ & $(4 \cdot 7-15 \cdot 2)$ \\
& $3 \cdot 76$ & $4 \cdot 25$ & $6 \cdot 62$ & $10 \cdot 7$ \\
\hline
\end{tabular}

The numbers in square brackets refer to the number of experiments; S.E.M. or the range of the values (in brackets) is given; NPG-ase, $N$-acetylglucosaminidase.

- Specific activity of the enzyme in the sample. Units, as defined in the text.

+ For description of this fraction, see text and legend to Table 1.

$\ddagger$ The sucrose gradient was $20-50 \%$. Centrifugation was for $2.5 \mathrm{hr}$ at $63,500 \mathrm{~g}$ (see text for details).

considerable regional differences, a presumed reflection of differences in bound-NANA content of the different brain regions, recently shown to characterize the gangliosides of seven different areas of the human brain (DoMINICK and GIELEN, 1968). In agreement with the recent reports (SPENCE and Wolfe, 1967; BRUNNGRABER, DeKIRMENJAN and BROWN, 1967; LAPETINA, Soto and DE RoBERTIS, 1968), the RSA of boundNANA was highest in the microsomal fraction (Fig. 3, medium A). High values of 
RSA also characterized the cortical and to a lesser extent the thalamic myelin fractions ( $M y$ ) but not the myelin of the hypothalamus. Recently, Suzuki, PodusLo and NorTON (1967) showed ganglioside NANA to be a constituent (or a contaminant?) of rat-brain myelin. Bound-NANA was virtually absent from fraction $L y$ (BRUNNGRABER et al., 1967) indicating: (a) that the lysosomal membrane differs from the synaptic membrane (Lapetina, Soto and De Robertis, 1967; Sellinger, Borens and NoRDRUM, 1969) and from the membranes of the endoplasmic reticlum (fraction Mic, see above); and (b) that fraction $L y$ is not contaminated by synaptic vesicles (WHITTAKER, 1966; Vos, KurIYAMA and RoBerTs, 1968).

Placing excised brain tissue into media of decreasing tonicity for purposes of homogenization and differential centrifugation (Fig. 1) resulted in a gradual loss of the two hydrolases from fractions $L y$ and NEML. The direction of this loss was not identical for the two enzymes, as was attested by the significantly lower percentage of NPG-ase compared to sulphatase appearing in fraction $S$ and by an equivalently higher proportion of NPG-ase activity found in fraction Mic, presumably because in the latter case enzyme was still associated with small membrane fragments of the disrupted lysosomes. These findings seem to demonstrate a tighter linkage for NPG-ase to lysosomal structure than for sulphatase, in agreement with the observations of BECK and TAPPEL (1968) on hepatic lysosomal NPG-ase and with those of BowEN and RADIN (1968) on cerebral lysosomal cerebroside galactosidase. The findings are strengthened by present results (Fig. 3) which showed higher values for RSA of NPGase than for sulphatase in fraction Mic of all three neuroanatomical regions examined and in both hypotonic media (B and $\mathrm{C}$ ). The proportion of the total activity of the two hydrolases in fractions $L y, S$ and $N E M L$ following their isolation in various media (Fig. 2) shows that outright solubilization of the enzymes may be avoided, provided $250 \mathrm{~mm}$-sucrose is used from the start of the fractionation. The irreversibility of the solubilization process is indicated by the lack of effect of a return to isotonicity immediately after homogenization in tris $+\mathrm{Mg}$ (fraction $S$, bar-sets 4 and 5). When isotonic sucrose was supplemented with $\mathrm{Mg}$ (bar-set 2), solubilization of either hydrolase was minimal, indicating that $10 \mathrm{mM}-\mathrm{Mg}$ did not elicit the egress of these proteins from the lysosomes but instead produced clumping of the particles and caused them to sediment with fraction $N E M L$. A similar effect of $10 \mathrm{mM}-\mathrm{Mg}$ (and $\mathrm{Ca}$ ) was recently reported for lysosomes isolated from mouse liver (VERITY, CAPER and BRown, 1968). In the absence of sucrose (Fig. 2, bar-sets 1 and 3) $10 \mathrm{mM}-\mathrm{Mg}$ was associated with doubling of the hydrolase content of fraction $N E M L$ and a parallel reduction of fraction Mic. Protein (Table 2, lines 1 and 2) shifted in a similar fashion.

Several recent reports have focused on questions of the change of the complement of lysosomal enzymes, of the change of the internal structural association of lysosomal hydrolases, and of the change in the physical state of the granule during the process of cerebral maturation (TAHA and Carubelli, 1967; Carubelli, 1968; Verity and Brown, 1968; Bowen and RAdIN, 1969). Suggestions to explain the recorded observations were: (a) that parallel developmental changes in the amounts of endogenous substrate (cerebroside, ganglioside etc.) and total hydrolase activity somehow regulate changes in the physical state of the lysosome during development; or (b) that intrinsic, age-dependent differences in constitution of the lysosomal membrane determine the changing pattern of the interactions between the interior and the exterior of the lysosome during development. It has been stated that 'the lysosome produced in the 
younger animal is more susceptible to lysis ... than the lysosome produced in the older animal' (AyOuB, 1967) and that 'lysosomal heterogeneity in which individual particles do not contain the same enzyme complement' accounts for the differences observed in the age-related activation of three lysosomal hydrolases of brain (VERITY and Brown, 1968). A similar proposal was made several years ago (SELLINGER et al., 1964) and evidence to validate it has been subsequently accumulated (SELLINGER and RUCKER, 1964; Mordoh, 1965; Hunter and Millson, 1966; Sellinger and Hiatt, 1968). The data in Table 3 and Fig. 4 support the concept of heterogeneity of lysosomes, particularly in terms of phenomena related to age, since they pinpoint significant differences for 12-day-old and adult lysosomes under identical test-conditions, in one case a purification step (Table 3 ) and in the other, a homogenization medium.

\section{REFERENCES}

Algert E. (1968) Z. klin. Chem. u. klin. Biochem. 6, 38.

Ayoub E. M, (1967) Nature (Lond.) 214, 705.

Azcurra J. M. and Sellinger O. Z. (1967) Brain Res. 6, 359.

Beck C. and Tappel A. L. (1968) Biochim. biophys. Acta (Amst.) 151, 159.

Bowen D. and Radin N. S. (1968) Biochim. biophys. Acta (Amst.) 152, 599.

Bowen D. and RAdin N. S. (1969) J. Neurochem. 16, 457.

Brunngraber E., Dekirmenian H. and Brown B. D. (1967) Biochem. J. 103, 73.

CARubelli R. (1968) Nature (Lond.) 219, 955.

Dixon J. S. (1967) Nature (Lond.) 15, 657.

Dominick E. and Gielen W. (1968) Z . physiol. Chem. 349, 731.

DVORAK K. (1967) Acta histochem. (Jena) 26, 54.

FroHWEIN Y. Z. and GATT S. (1967) Biochemistry 6, 2775.

GatT S. (1967) Biochim. biophys. Acta (Amst.) 137, 192.

Gordon M. K., Bensch K. G., Deanin G. G. and Gordon M. W. (1968) Nature (Lond.) $217,523$. Hunter G. D. and Millson G. C. (1966) J. Neurochem. 13, 375.

Kerekes M. F., Feszt T., Becus M. and Szekely C. (1968) Enzymol. biol. clin. 9, 152.

KhatTab F. I. (1967) Exp. Neurol. 18, 133.

Kreutzberg G. and Hager H. (1966) Histochemie 6, 254.

LApetina E. G., Soto E. F. and DE Robertrs E. (1967) Biochim. biophys. Acta (Amst.) $135,3$. Lapetina E. G., Soto E. F. and de Robertis E. (1968) J. Neurochem. 15, 437.

Lowry O. H., Rosebrough N. J., FARr A. L. and Randall R. S. (1951) J. biol. Chem. 193, 265.

MORDOH J. (1965) J. Neurochem. 12, 505.

Novikoff A. B. (1967) In The Neuron (Edited by HydEN H.) p. 319. Elsevier, Amsterdam.

Sellinger O. Z. and RuCKer G. (1964) Life Sci. 3, 1097.

Sellinger O. Z., Rucker G, and de Balbian Verster F. (1964) J. Neurochem. 11, 271.

Sellinger O. Z, and Rucker G. (1966) Life Sci. 5, 163.

Sellinger O. Z. and Hiatt R. A. (1968) Brain Res. 7, 191.

Sellinger O. Z. and Azcurra J. M. (1968) In Macromolecules and the Function of the Neuron (Edited by LoDIN Z. and Rose S. P. R.) p. 256. Excerpta Medica Foundation Press, Amsterdam. Sellinger O. Z. and Borens R. N. (1969) Biochim. biophys, Acta (Amst.) 173, 176.

Sellinger O. Z., Borens R. N. and Nordrum L. M. (1969) Biochim. biophys. Acta (Amst.) 173, 185. Spence M. W. and Wolfe L. S. (1967) Canad.J. Biochem. 45, 671.

Suzuki K., Poduslo S. E. and Norton W. T. (1967) Biochim. biophys. Acta (Amst.) 144, 375.

Taha B. H. and Carubelli R. (1967) Arch. Biochem. 119, 55.

VERITY M. A. and Brown W. J. (1968) J. Neurochem. 15, 69.

Verity M. A., CAPer R. and Brown W. J. (1968) Biochem. J. 109, 149.

Vos J., Kuriyama K. and Roberts E. (1968) Brain Res. 9, 224.

WARREN L. (1959) J. biol. Chem. 234, 1971.

WhitTaker V. P. (1966) Ann. N.Y. Acad. Sci. 137, 982. 